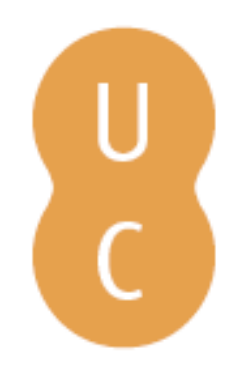

\title{
pombalina
}

\section{Joaquim dos Santos e Silva: um pioneiro português da Química moderna}

Autor(es): $\quad$ Formosinho, Sebastião J.; Herold, Bernardo J.; Cardoso, Augusto C.

Publicado por: Imprensa da Universidade de Coimbra

URL

persistente: $\quad$ URI:http://hdl.handle.net/10316.2/38451

DOI: $\quad$ DOI:http://dx.doi.org/10.14195/978-989-26-0764-1_15

Accessed : $\quad$ 26-Apr-2023 12:32:39

A navegação consulta e descarregamento dos títulos inseridos nas Bibliotecas Digitais UC Digitalis, UC Pombalina e UC Impactum, pressupõem a aceitação plena e sem reservas dos Termos e Condições de Uso destas Bibliotecas Digitais, disponíveis em https://digitalis.uc.pt/pt-pt/termos.

Conforme exposto nos referidos Termos e Condições de Uso, o descarregamento de títulos de acesso restrito requer uma licença válida de autorização devendo o utilizador aceder ao(s) documento(s) a partir de um endereço de IP da instituição detentora da supramencionada licença.

Ao utilizador é apenas permitido o descarregamento para uso pessoal, pelo que o emprego do(s) título(s) descarregado(s) para outro fim, designadamente comercial, carece de autorização do respetivo autor ou editor da obra.

Na medida em que todas as obras da UC Digitalis se encontram protegidas pelo Código do Direito de Autor e Direitos Conexos e demais legislação aplicável, toda a cópia, parcial ou total, deste documento, nos casos em que é legalmente admitida, deverá conter ou fazer-se acompanhar por este aviso. 
${ }^{1}$ Departamento de Química, Universidade de Coimbra

${ }^{2}$ Centro de Química Estrutural, Instituto Superior Técnico, Universidade Técnica de Lisboa sformosinho@qui.uc.pt; cardoso@ci.uc.pt

Joaquim dos Santos E Silva: Um Pioneiro Português da Química Moderna

Sebastiâo J. Formosinho ${ }^{1}$, Bernardo J. Herold ${ }^{2}$ E Augusto C. Cardoso ${ }^{1}$

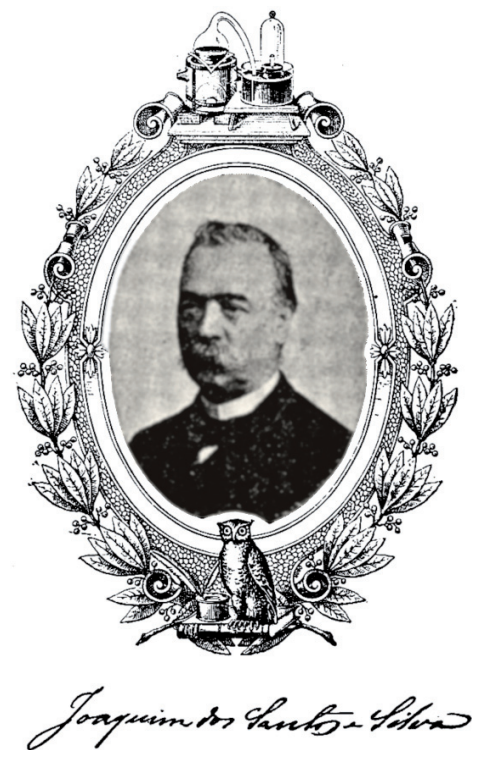

Joaquim dos Santos e Silva nasceu em Bruscos, na freguesia de Vila Seca, concelho de Condeixa-a-Nova em 25 de Janeiro de 1842. Em 1859, com dezassete anos, veio para Coimbra para seguir a carreira de Medicina, tendo mudado, por falta de recursos, para Farmácia, fazendo para tal fim, de 1862 a 1868, os preparatórios do Liceu. Durante este período, as suas aptidões para os estudos de Química manifestam-se no tirocínio realizado no Laboratório Químico da Universidade que o motivaram a apresentar um requerimento para o lugar de «ajudante do Laboratorio Chymico» ${ }^{1}$. O Conselho inicialmente rejeitou o pedido, mas retrocedeu na decisão e em 1 de Novembro 1864 Santos Silva inicia a tarefa que vai cumprir até 18 de Outubro de1868.

Na década de 1860, nomeadamente no ano de 1864, quando o jovem estudante de Farmácia faz o seu pedido era Director da Faculdade de Philosophia e também do Laboratorio Chymico o Lente de Prima, Decano António José Rodrigues Vidal (1808-1879). No início do ano escolar de 1861-1862 fora concretizada a reforma que vinha 
sendo reclamada desde 1851, e que iria regular o ensino até 1885. A Química ficava distribuída pelo $1 .^{\circ}$ ano com Chimica Inorgânica e Metalurgia cuja regência estava atribuída ao Lente Cathedratico Miguel Leite Ferreira Leão (1815-1880) e ao Substituto Graduado Albino Augusto Giraldes Moraes (1825-1888) e no 2. ${ }^{\circ}$ ano com Chimica Orgânica e Analyse Chimica, atribuída ao Lente Cathedratico Joaquim Augusto Simões de Carvalho (1821-1902) e ao Substituto Graduado Albino Augusto Giraldes. Em Outubro de 1865 toma posse de Director do Laboratório Miguel Leite Ferreira Leão, cujas funções se vão prolongar até 1877. Durante estes 12 anos o Laboratorio Chymico vai atravessar uma importante fase de crescimento e mesmo de viragem. Em 1869, toma posse de Reitor da Universidade «... Julio Máximo d'Oliveira Pimentel, Visconde de Villa-Maior, Par do Reino, Lente Jubilado da Eschola Polytechnica de Lisboa, Socio effectivo da Academia Real das Sciencias, Commendador da Ordem de Nossa Senhora da Conceição de Villa-Viçosa, Official da de Torre e Espada do valor lealdade e mérito, e da Legião d'Honra»².

Na Congregação da Faculdade de Philosophia de 18 Junho de 1857, «... ponderando-se a conveniência de enviar um ou mais vogaes do Conselho a estudar nos paizes estrangeiros a parte pratica dos ramos mais importantes das sciencias physicas e naturaes, decidiu-se encarregar d'esta commissão o dr. Mathias de Carvalho, que se ofereceu para este serviço [tendo sido encarregado durante a sua viagem em França] de contractar um homem practico para vir a Coimbra ensinar os guardas e ajudantes dos estabelecimentos de história natural» ${ }^{3}$. Não há notícias dos resultados desta acção.

Cerca de dez anos depois, na reunião de 13 de Novembro de 1868 do Conselho: "[...] O Ex ${ }^{\text {mo }}$ Vice-Reitor apresentou uma Portaria do Ministerio do reino de 9 de novembro de 1868, pela qual o Conselho fica auctorisado a contractar por cinco annos um chimico estrangeiro [...] Por esta ocasião todos mostraram desejos de auxiliar o $\mathrm{Ex}^{\mathrm{mo}}$ Diretor do Laboratorio, o que Sua Ex ${ }^{\mathrm{a}}$ agradeceu e o Sr Dr. Albino lembrou a conveniencia de executar já certos trabalhos, taes como levantar a planta de todo o Laboratorio, arranjar a casa, que n'este edifício há, para habitação do Chimico [...] O Conselho nomeou para esse fim uma comissão composta dos $\mathrm{Sr}^{\mathrm{s}} \mathrm{DD}^{\mathrm{rs}}$ Leão, Viegas e Albino» ${ }^{4,5}$. Em Congregação de 14 de Dezembro de 1868 «[...] O Sr. Dr. Viegas informou que a comissão encarregada dos melhoramentos do Laboratorio tinha formulado o contracto que devia ser celebrado com o chimico que por auctorização do Governo devia ser contractado para aquelle estabelecimento; que tinha escripto e mandado aquelle contrato ao Sr Hofman, assim como tinha escripto ao Sr. Dr Peters, pedindo-lhe o seu auxilio, ao que elle prontamente tinha acedido" ${ }^{6}$. $\mathrm{Na}$ Congregação de 25 de Janeiro de 1869 «...O Sr. Dr. Santos Viegas leu uma carta do Sr.Hofman relativa ao chimico que devia vir para o Laboratorio da Universidade. O Conselho encarregou o mesmo vogal de falar com o $\mathrm{Ex}^{\mathrm{mo}}$ Vice-Reitor para este pedir esclarecimentos ao Governo sobre o modo de pagamento do ordenado d'aquelle Chimico, uma vez que foram suprimmidos os prémios, por cuja verba devia ser pago» ${ }^{7}$. Na congregação de 22 de Fevereiro de 1869 «...o $\mathrm{Ex}^{\text {mo }} \mathrm{D}^{\text {ro }}$ Viegas declara que não havia duvida sob o pagamento do ordenado do Chimico da parte do Governo que já tinha sido escripto ao Sr. Tollens» ${ }^{8}$. Na Congregação do dia 9 do mês seguinte «...O Ex ${ }^{\text {mo }}$ $\mathrm{D}^{\text {ro }}$ Viegas participou que o Sr Tollens tinha aceitado o logar, que lhe tinha sido oferecido para dirigir os trabalhos de chimica. [Nessa mesma reunião] Foi lido e aprovado o contracto celebrado com o Snr Tollens e resolveo o Conselho, que fosse assinado 
pelo $\mathrm{Ex}^{\mathrm{mo}}$ Vice-Reitor e pelo Secretário da Faculdade» ${ }^{9}$. Dá-se pois conta que a indicação de Tollens terá cabido a Hoffman.

No início do ano lectivo 1868-1869 [entre maio e Julho de 1869] chega a Coimbra, vindo de Paris onde trabalhava com Charles Adolphe Wurtz (1817-1884), o químico alemão Bernhard Christian Gottfried Tollens (1841-1918) com a finalidade de dirigir e o reorganizar o estudo prático do Laboratório Químico. "Tinha um vencimento cerca de três vezes superior ao dos lentes mais qualificados e tinha habitação em casa própria no Laboratório Chymico» ${ }^{10}$. Santos Silva teve a concessão especial de trabalhar no seu laboratório e receber instruções deste químico alemão.

Tollens esteve em Coimbra aproximadamente um ano. Na reunião de 21 de Janeiro de 1870, o «... Ex ${ }^{\text {mo }}$ Reitor deu parte ao Conselho de que o Sr Tollens tinha dado a sua demissão do lugar que ocupava. O Conselho reconhecendo a grande necessidade que ha em prover aquelle lugar, pedio ao $\mathrm{Ex}^{\mathrm{mo}}$ Reitor, que quisesse promover, auxiliado por alguns membros do Conselho, a acquisição d'algum individuo, que tivesse as necessárias habilitações. O Ex ${ }^{\mathrm{mo}}$ Reitor prometeu empregar todos os meios de que podesse dispor» 11. De facto, Tollens rescinde o contrato em Março de 1870 para ir para a Universidade de Göttingen como assistente de Friedrich Wöhler (1800-1882), tendo decorridos dois meses obtido a sua Habilitation e passado a ocupar a posição de Privatdozent.

Ferreira de Leitão, à época director do Laboratorio Chimico, foi quem mais de perto acompanhou a acção de Tollens, no que diz respeito à "natureza e extensão do ensino practico" referia no seu Relatório de 1870:

«... Neste anno, porém, deu-se mais desenvolvimento a estes trabalhos debaixo da direção do dr. Tollens, particularmente no estudo das reaçôes. Este ensino, todavia, ficou limitado a dezeseis alumnos, pois era o numero que comportavam as quatro mesas de trabalho; nem mesmo sem nenhum outro pessoal se podia cuidar de maior numero e manter-se o policia necessaria dentro do estabelecimento, de sorte que aquelle ensino se fizesse com proficiencia para os alumnos, e sem prejuizo do laboratório [...] Em todos os dias da semana havia trabalhos practicos desde as 10 horas da manhã até ás tres da tarde, com exceção dos sabbados, que eram destinados á limpeza do edificio e reforma dos reagentes, versando, como disse, quasi exclusivamente sobre o estudo das reaçôes, e preparação de reagentes, ou sua purificação. [...] É, todavia, minha opinião, por o ter observado muitas vezes, que aquelle ensino é profícuo, e alguns alumnos estão bastantemente adiantados, especialmente no estudo das reaçôes...» ${ }^{12}$. Relativamente à perda pela saída de Tollens refere: «...Ha pouco lá se foi o dr. Tollens [...] ahi estamos novamente sem chefe de trabalhos practicos, e quem possa continuar no laboratório um serviço que todos os países apreciam devidamente, pois se tem feito sentir na civilização dos povos o seu benéfico e maravilhoso influxo. Ámanhã vira um outro extrangeiro imital-o de novo, para d'ahi a pouco, num período mais ou menos longo, nos deixar também nas mesmas condições de não haver nunca na Faculdade quem continue, e nós sempre á mercê de extrangeiros...» ${ }^{13}$.

A substituição de Tollens, apesar de envolver directamente o Reitor da Universidade Júlio Máximo de Oliveira Pimentel, foi um pouco tormentosa. Na Congregação de 8 de Fevereiro de 1870, o "[...] Ex ${ }^{\text {mo }}$ Reitor deu parte de que tinha escrito ao Snr Wurtz, relativamente ao empregado para o Laboratorio, que devia substituir o Snr Tollens» ${ }^{14}$ e na Congregação de 5 de marco de 1870 o «[...] Ex ${ }^{\text {mo }}$ Reitor deu parte que o Snr Roberto Duarte da Silva ${ }^{15}$ tinha aceitado o logar de chefe de trabalhos no Laboratorio 
com o ordenado 450:000 annuais. Participou também que elle não podia vir antes d'outubro, atendendo a que tinha trabalhos começados que desejava concluir. O Snr $\mathrm{D}^{\mathrm{r}}$ Viegas propos que se fizesse já o contracto, concedendo o Conselho auctorização para aquelle Senhor estar em Paris ate outubro. O Conselho approvou» ${ }^{16}$. Porém, na reunião de 7 de maio de 1870, o "[...] Ex ${ }^{\text {mo }}$ Reitor deu parte ao Conselho, que já não vinha para o Laboratório o chimico Roberto Duarte da Silva, por este se ter recusado a assignar o contracto que lhe fora enviado» ${ }^{17}$. Face à situação criada, na Congregação de 4 de Junho de 1870, o director do Laboratório, Ferreira Leão «[...] reconhecendo a necessidade do ensino pratico de Chimica e as dificuldades que haveria em quanto na Universidade não houvesse algum professor habilitado com estudos feitos nos payses a onde a sciencia se acha mais adiantada propos que se representasse ao Governo para que fosse mandado estudar no estrangeiro o $\mathrm{D}^{\mathrm{r}}$ Adriano de Paiva Leite Brandão ${ }^{18}$ Depois d'alguma discussão resolveo-se que ficaria adiada a resolução deste negocio» ${ }^{19}$. Apesar de na reunião seguinte de 7 de Julho, o Conselho ter decido favoravelmente Paiva Brandão, no tempo, a situação retrocede sendo proposto na sua vez Santos e Silva. Não obstante a sua aprendizagem com Tollens, Santos e Silva não surge como a primeira prioridade da Universidade, pois ainda não havia terminado o curso de Farmácia.

A preferência dada a Santos e Silva para estagiar na Europa em detrimento de Adriano de Paiva, deve-se à interferência do Reitor que redige, em 8 de agosto de 1871, o seguinte pedido dirigido ao Governo:

«III ${ }^{\mathrm{mo}}$ e $\mathrm{Ex}^{\mathrm{mo}} \mathrm{S}^{\mathrm{ro}}$. O Laboratorio Chimico da Universidade está depois da sahida do $\mathrm{D}^{\text {ro }}$ Tollens, em abril do ultimo anno sem preparador e chefe dos trabalhos praticos devidamente habilitado. Sabe V. Exa que um estabelecimento d'aquella ordem não pode dispensar um chimico habituado ás manipulações e preparações, não só para coadjuvarem os professores nas experiencias e demonstrações dos cursos, mas ainda para dirigir os alunnos nos exercícios práticos, ensinando-lhes palpavelmente os methodos de investigação e analyses, sem os quais o ensino theorico é de nenhum valor. Para remediar até ao ponto da retirada do $\mathrm{D}^{\text {ro }}$ Tollens foi encarregado de continuar a direção prática dos estudantes de pharmacia um antigo alunno que trabalhara com o $\mathrm{D}^{\text {ro }}$ Tollens durante o pouco tempo que este exerceu a direção dos trabalhos de laboratório. Desempenhou elle muito regularmente este serviço e tem mostrado bastante aptidão e desejo de se instruir: falta-lhe porém ainda o indispensável conhecimento dos methodos e manipulações que só a pratica dos grandes laboratórios e a convivência com os homens eminentes da sciencia pode fornecer. É com tudo com este indivíduo muito aproveitável e offerece todas as garantias de progresso, podendo tornar-se excelente preparador e chefe de trabalhos se se lhe proporcionarem os meios de ir completar os estudos praticos em algum dos laboratórios mais acreditados da Alemanha. O sacrifício que para isso o estado tem que fazer é de minima importância em relação ás vantagens que se podem colher para a instrucçao pratica dos alunos, e para tirar o Laboratorio da Universidade da espécie de marasmo em que se acha. Permettindo V. Ex ${ }^{a}$ que Joaquim dos Santos e Silva, que é o individuo a que me refiro, passe a estudar em alguns laboratórios d'Allemanha, durante um ano, a pratica das operaçôes necessárias para os cursos de chimica com um subsidio sufficiente, que não poderá exceder a quantia de $50 \$ 000$ rs mensaes, e viagens pagas, teremos conseguido remediar uma grande falta, evitar uma vergonha que vexa a Universidade, e fazer um bom serviço á instuicçao publica...» ${ }^{20}$. 
Igualmente favoreceram a escolha de Santos e Silva alguns professores «influentes da Faculdade [que] pensaram em aproveital-o para occupar um dia uma posição regular no laboratório»" ${ }^{21}$.

Em 8 de Setembro de 1871, Santos e Silva parte para Universidade de Göttingen onde no período de 7 de Outubro 1871 a 8 de agosto a 1872 segue os cursos de química mineral e química aplicada, dados além de Tollens, por Wöhler e Hans Hübner (1837-1884). «... Depois, auctorisado pelas portarias de 12 de junho e 23 de julho de 1872, passou para o Instituto chimico de Bonn onde sob a direção e conselho do ilustre professor Kekulé [Friedrich August Kekulé (1829-1896)] e do então seu assistente Wallach [Otto Wallach (1847-1931)] se ocupou em trabalhos de chimica orgânica» ${ }^{22}$.

Além das pisadas deixadas por Santos e Silva, através da publicação das pesquisas que efectuou no laboratório de Kékulé, há um curioso testemunho deixado por Jacobus Henricus van 't Hoff (1852-1911), que viria a ser um dos criadores da nova disciplina de química física e da estereoquímica, laureado Nobel de 1901. Quando van't Hoff veio trabalhar com Kékulé em 1872, foi a sua primeira viagem ao estrangeiro. Subiu o Reno num vapor e ficou entusiasmado com a paisagem montanhosa à volta de Bona, bem diferente da planície da sua cidade natal de Roterdão. Numa carta ${ }^{23}$ que, mal chegado a Bona, escreveu à mãe, descreve a paisagem com palavras que podiam ser as do seu poeta predilecto Lord Byron à chegada a Sintra. O cúmulo do encantamento com tanto exotismo parece ter sido no entanto o seu encontro com Santos e Silva. Senão leia-se o seguinte excerto da sua carta à mãe:

«[...] Pelas 9 horas [...] comprei alguns livros e comecei imediatamente a estudá-los. No entanto fui perturbado pela subida de bagagens ao meu andar; a estas seguiu-se o meu vizinho, um português, Santos. Quando podia supor que este já tinha recuperado o fôlego, fiz-lhe uma visita. Conversámos em francês; ele já é bastante velho $\left(27\right.$ anos $\left.{ }^{24}\right)$, muito barbudo, com feições meridionais, morenas e ossudas. Não sendo feio, tem a aparência dum salteador e constitui o oposto àquilo que aqui se chama "uma lua cheia". É um químico que foi enviado para aqui pelo seu governo, para estudar os melhoramentos alemães e os poder introduzir em Portugal. Por enquanto, temos passado muito tempo juntos; almoçámos duas vezes em Bona, para podermos comparar os vários restaurantes. No Domingo caminhámos para o "Drachenfels", passando por "Kreuzberg" e "Godesberg". Proximamente vou-lhe escrever mais acerca dele. Por enquanto ainda está envolto no manto colorido e feiticeiro da novidade» ${ }^{25}$.

Com o regresso de Santos e Silva a Portugal a 8 de agosto de 1873, acompanhado de elogiosos documentos subscritos pelos professores com que trabalhou, designadamente Wöhler e Kekulé «attestando exemplar applicação e assiduidade, zelo infatigavel e aptidão para os trabalhos chimicos» ${ }^{26} \operatorname{logo}$ se procedeu ao pedido de criação do lugar sob os mesmos princípios com que havia sido contratado Tollens. Por contrato assinado em 12 de Novembro, Santos e Silva ocupa o lugar de chefe dos trabalhos práticos, com o vencimento de 500\$000 reis anuais. O contrato foi por cinco anos; mas, com o assentimento e voto da Faculdade, continuou a servir findo esse prazo, até que a portaria de 20 de maio de 1880 cria o lugar, e Santos e Silva é provido definitivamente por decreto de 23 de Junho deste mesmo ano. 
Dois anos académicos na Alemanha era o período mínimo que um estudante requeria, no tempo, para fazer o doutoramento, mas, como referido, Santos e Silva ainda não havia alcançado o primeiro grau universitário. Fê-lo já regressado ao país. Em 9 Abril 1875, realiza o exame final do curso de Farmácia, sendo o júri constituído pelo presidente e primeiro arguente António Egípcio Quaresma Lopes (1817-1911) [lente de Matéria Médica e Farmacêutica da Faculdade de Medicina da Universidade de Coimbra], João Jacinto da Silva Correia (1843-1913) [lente substituto da mesma Cadeira] e Cândido Joaquim Xavier Cordeiro (1808-1881) [Administrador do Dispensatório Farmacêutico da Universidade de Coimbra]. Foi aprovado plenamente ${ }^{27}$.

Para além de chefe dos trabalhos práticos do "Laboratorio Chymico» que ocupou até ao fim da vida, Santos e Silva exerceu outras funçōes. Quando pela Carta de Lei de 17 de agosto de $1899^{28}$, regulamentada pelo Decreto de 16 de Novembro de 1899 ${ }^{29}$ foram reformados os serviços médico-legais e criados os lugares de químicos analistas, é nomeado "chimico analysta da terceira circumscripção de Coimbra do Conselho medico-legal», por despacho 23 de Novembro de 1899. Na sequência da reforma do ensino da Farmácia estabelecida por Carta de Lei de 27 de Novembro de 1902 30 é nomeado, por Decreto de 27 de Novembro de 1902, «[...] professor da $4^{\mathrm{a}}$ cadeira da Escola de Pharmacia, annexa à faculdade de medicina da referida Universidade» ${ }^{31}$, tendo assumido a regência da referida cadeira, "Analyses toxicológicas, chimica legal, alteraçōes e falsificaçōes de medicamentos e alimentos" [com Pratica no laboratorio chimico], nos anos letivos de 1903-1904, 1904-1905 e 1905-1906². Foi Sócio efectivo do Instituto de Coimbra, Sócio Honorário da Sociedade Farmacêutica Lusitana, Sócio da Sociedade Química de Berlim.

Se bem que nunca tenha sido professor na Faculdade de Filosofia, era tido em muita elevada consideração pelos seus colegas químicos, mormente pelo Director do Laboratório Química, Francisco José de Sousa Gomes (1860-1911), lente de Química Inorgânica na Universidade de Coimbra, e que o substituiu no cargo de «Chimico Analysta do Conselho Medico Legal de Coimbra» aquando da sua morte prematura aos 64 anos de idade. O seu retrato figura na galeria de retratos de Directores do Laboratório Químico e do Departamento de Química da Universidade de Coimbra, apesar de não ter sido seu Director ${ }^{33}$.

A genealogia científica de Santos Silva congrega a influência de químicos bem eminentes e testemunha que ele foi um pioneiro precoce do "químico moderno português» (tabela 1) ${ }^{34}$. Mas ainda não havia estruturas para que Santos e Silva continuasse a investigar e a criar escola em Coimbra, nem o seu estatuto académico o permitia. Só mais de sessenta anos depois, já na década de trinta, se vem a retomar política semelhante na Universidade de Coimbra.

\begin{tabular}{|l|l|l|l|}
\hline \multicolumn{5}{|c|}{$\begin{array}{c}\text { Joaquim Santos-Silva } \\
1842-1906\end{array}$} \\
\hline Bernhard Tollens & $1841-1918$ & Friedrich Kekulé & $1829-1896$ \\
\hline Rudolph Fitttig & $1835-1910$ & Heinrich Will & $1812-1890$ \\
\hline Friedrich Wöhler & $1800-1882$ & Justus Liebig & $1803-1873$ \\
\hline Jöns Jacob Berzelius & $1779-1884$ & Karl Kastner & $1783-1857$ \\
\hline
\end{tabular}

Tabela 1 - Genealogia científica de Joaquim Santos e Silva. 


\section{CONTRIBUiÇŌES CIENTÍFICAS}

Durante a sua estada na Universidade de Bonn, em 1873, Kékulé sugeriu a Santos e Silva estudar a reacção de bromação do ácido canforacarboxílico, o que este fez com sucesso, isolando, analisando e caracterizando o ácido bromocanforacarboxílico, um composto novo. Este trabalho integrou-se numa série de numerosos trabalhos sobre a cânfora e os seus derivados da escola de Kékulé. Enquanto este, na química do benzeno e dos seus derivados, nessa altura já tinha vencido os principais obstáculos para o esclarecimento das suas estruturas moleculares, na química da cânfora ainda estava muito longe de atingir essa meta. Kékulé em 1873 ainda proporá uma estrutura monocíclica para a cânfora. O trabalho de Santos e Silva aumentou o acervo dos conhecimentos nessa área. Publica um artigo (figura 1) ${ }^{35}$ sobre estes estudos com a afiliação da Universidade de Bona e "relatado" por Kekulé. Uma prática relativamente corrente em laboratórios alemães, segundo Richard Anschütz (1852-1937) na sua biografia de Kekulé ${ }^{36}$. Os seus resultados não foram porém cruciais para a determinação da estrutura da cânfora que só viria a ser determinada correctamente em 1893 por Julius Bredt (1855-1937) ${ }^{37}$ como estrutura bicíclica. Assim o seu trabalho ficou um pouco esquecido pela história da Química.

Regressado a Portugal continua as suas investigaçôes realizadas em Bona e publica, em duas partes, um artigo sobre a análise química de alguns derivados da cânfora (figura 2) ${ }^{38}$. Na primeira parte o estudo incide sobre o ácido canfocarbónico (canforacarboxílico na nomenclatura actual) e sobre outros derivados, tendo obtido borneol em elevados estado de pureza. Na segunda procura «[...] obter alguns derivados ethereos do borneol ou alcool campholico, seguindo para isso os processos geraes, por meios dos quais se obtêm os derivados correspondentes do álcool ordinário e dos outros alcooes da mesma serie, não tanto com o fim de verificar as analogias entre o álcool campholico e os alcooes da serie gorda, como para enriquecer a coleção de chimica orgânica do laboratório» ${ }^{39}$.

Em 1874, publica um artigo sobre a essência da pimenteira falsa ${ }^{40}$. Reconhece como componente principal uma essência hidrocarbonada de fórmula $\mathrm{C}_{10} \mathrm{H}_{16}$, com propriedades físicas (ponto de ebulição, densidade...) muito próximas do eucaliptol. Em 1877, com o apoio de Júlio Augusto Henriques (1838-1928) (na época director do Jardim Botânico da Universidade) fez a análise qualitativa e quantitativa dos alcalóides de algumas quinas da espécie Cinchona succirubra, cultivadas em S. Tomét ${ }^{1}$, revelando quantidade relativamente elevada de quinina e cinchonina, assunto a que volta em $1881^{42}$. Um estudo com enorme importância para um produto que estava a ser tomado como um bem económico de indiscutível valor ${ }^{43}$. 


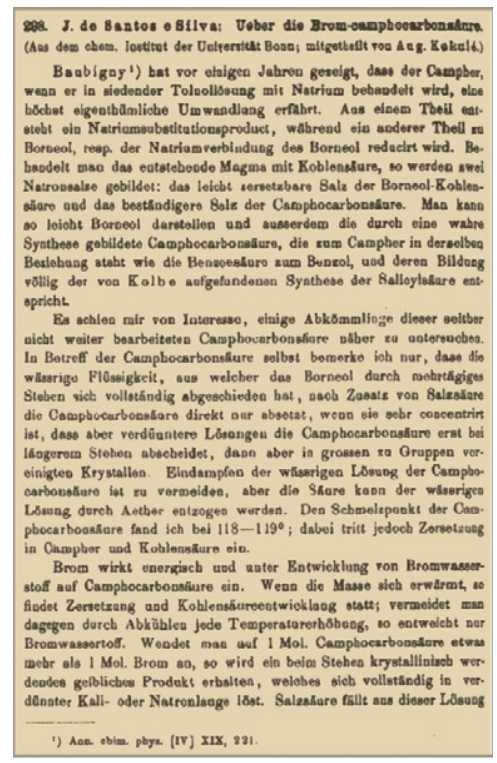

Figura 1 - Reprodução da separata sobre derivados da cânfora publicada na Alemanha.



Figura 2 - Reprodução da separata sobre alguns derivados da cânfora.

A sua obra química mais extensa e interessante é do domínio da "química hidrológica". «[...] Com todo o escrúpulo que caracterizavam os seus trabalhos, apresentando os resultados com todos os pormenores, realizou analise química de muitas das principais nascentes de águas minerais do País» ${ }^{44}$. Realiza análises químicas das principais águas minerais do país. Estas análises, pelo rigor dos resultados analíticos apresentados, contribuíram para o desenvolvimento da hidrologia nacional. Não podemos deixar de antecipar que, em 1874, Santos e Silva «a instâncias do seu amigo, Visconde Vila Moura [o autor queria referir-se ao Reitor da Universidade Visconde de Vila Maior] publicou o primeiro guia português de análise química, baseado na prática do laboratório, e intitulado Elementos de Analyse Chimica Qualitativa. Coube-lhe a glória de ter sido o primeiro português que, entre nós, difundiu os conhecimentos de análise» ${ }^{45}$. Não admira pois que aquando da realização da sua primeira análise, a fonte de água férreas na estrada da Beira, as linhas do seu plano de acção fossem bem explicitadas:

«[...] Descreverei minuciosamente as operações da analyse qualitativa e quantitativa, a fim de que, em todo o tempo homens competentes possam dar ao meu trabalho o devido valor. Similhante descripção poderá, talvez, parecer superflua attendendo a que as substancias que ordinariamente mineralisam as água podem reconhecer-se facilmente por meios d'um pequeno numero de reagentes [...] Mas é certo, por outro lado, que nenhuma confiança pode inspirar o laconismo e expressões vagas d'aquelles analystas, que, desconhecidos na sciencia, se limitam a dizer, por exemplo: - a agua tractada convenientemente de chloruretos alcalinos... [...] ha de o leitor acreditar piamente em que o analysta soube escolher d'entre os differentes methodos, aconselhados por auctoridades scientificas de bem merecido nome [...] sendo certo porém, que nem todos os que têm publicados analyses d'aguas mineraes estão nestas condiçôes»" ${ }^{46}$. 
Assim procede no estudo da água referida, Santos Silva começa por descrever a nascente «... A collocação d'algumas bombas no talude da estrada da Beira, nos fins de agosto de 1875, deu lugar à descoberta d'um abundante manancial de águas ferreas juncto da cidade de Coimbra [...] são tiradas, por meio d'uma bomba, de profundidade de 4 a 5 metros a baixo do leito do Mondego, na margem direita a poucos metros de distância da escada do caes do Cerieiro [...] com uma temperatura de $16^{\circ}, 5$ a $17^{\circ}, 5 »^{47}$. Refere que tinha sido feito anteriormente um ensaio por Xavier Cordeiro «[...] com o fim unico de verificar se era o carbonato ou o sulfato de ferro que as mineralisava, limitando-se a ferver uma certa quantidade em um balão, de que lhe resultou um depósito ocroso» ${ }^{48}$. Chama a atenção para o facto de estudos recentes internacionais revelarem que a maior parte das águas férreas eventualmente conterem ácido arsénico, cobre, etc., que mesmo em quantidades mínimas podem ser prejudiciais ao organismo. De seguida, divide o seu trabalho em três partes. Uma relativa ao estudo de parâmetros físicos designadamente, sabor, cheiro, densidade. Outra, à análise química qualitativa, envolvendo uma série de ensaios químicos, que descreve de modo muito pormenorizado, remetendo frequentemente para o seu Elementos de Analyse Chimica Qualitativa. Começa por realizar, de um modo sistemático, uma série de ensaios para avaliar o comportamento da água com recurso aos "reagentes ordinários" [nitrato de prata (acido nitrico), chlorureto de bario (e acido chlorhydrico), chlorureto de bario ammoniacal, acido chlorhydrico, tintura de noz de galha, prussiatos de potassio, oxalato de ammonio e phosphato de sodio] e do resíduo sólido com recurso a um espectrómetro e a ensaios de chama com vidro azul. Conclui pela presença das substâncias seguintes: "... chloro, silica, acido sulfurico, acido carbonico, acido phosphorico, potassa, soda cal, magnesia, alumina (vestígios), ferro, manganés, matérias orgânicas [...] Depois de ter buscado inutilmente, o ácido arsénico, o estanho e o cobre, etc., [...] pareceu-me de importância muito secundaria proceder a investigaçôes tendentes a descobrir o bromo, o iodo, o fluor, o boro, o acido azotico, a baryta, a stronciana, o ammoniaco e outros corpos, que têm sido encontrados algumas vezes, em pequeníssimas quantidades, em certas aguas mineraes» ${ }^{49}$. Uma terceira, a análise química quantitativa das espécies químicas presentes e do resíduo sólido, por métodos gravimétricos. Termina, que "todo o ferro" se encontra "no estado de carbonato ferroso ou de protoxido de ferro», e após apresentar um «mappa comparativo das aguas mineraes da estrada da Beira com algumas aguas carbonatadas férricas do ducado de Nassau (Allemanha) analysadas por Fresenius [químico alemão Carl Remigius Fresenius (1818-97)]" 50, Santos e Silva refere um conjunto de cuidados a ter em consideração quando da recolha e transporte dos recipientes de modo a que a água mantenha as suas características.

De uma maneira geral nas análises subsequentes segue como padrão o protocolo utilizado na análise à água da estrada da Beira. Sequencialmente analisa as águas minerais das Caldas da Rainha, 1876, as de Bem-Saúde, 1880, as de Vidago fonte Campilho,1884, Amieira, 1885, as das Pedras Salgadas, 1887, de Vizela, 1888, as de Piedade ou Fervença, em Alcobaça, 1889 e 1894, as de Caldelas [em colaboração com Sousa Gomes], 1890, as de Marvão, 1891, as de Cucos, 1892, as de Alcanhōes 1893, as das Murtas, em Amarante, 1894, as de Santo António de Tavira, 1899, etc. Publica muitos dos resultados obtidos em revistas como o Instituto de Coimbra ${ }^{51}$. 


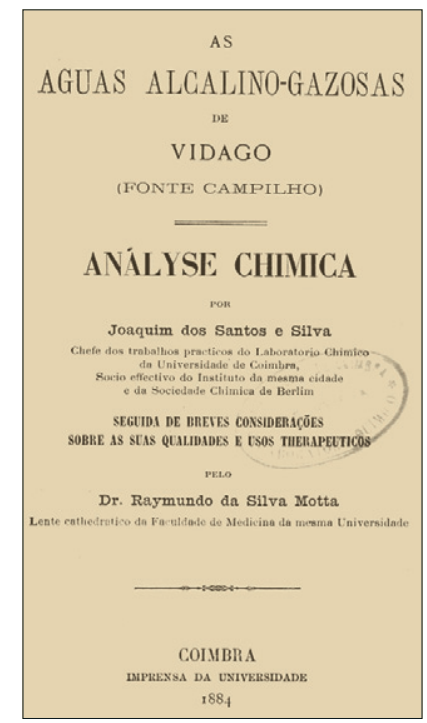

Figura 3 - Folha de Rosto da separata da análise química das Águas Alcalino-Gazosas de Vidago (Fonte Campilho) (1884).

No estudo das águas da nova nascente termal das Caldas da Rainha faz uma comparação dos resultados da sua análise com os de análises realizadas anteriormente, pelo químico inglês William Withering (1741-99) em $1795^{52}$, por Júlio Máximo de Oliveira Pimentel [Visconde de Vila Maior] em 1849 e $1858{ }^{53}$ e por Agostinho Vicente Lourenço (1822-1893) em 186754, concluindo haver concordância com análises feitas por Oliveira Pimentel e que, em pouco, diferem das realizadas por Agostinho Lourenço; mas, contrariamente, os valores referidos na análise de Withering representariam aproximadamente o dobro dos valores encontrados nas outras três análises. Santos e Silva referia que se "...admittirmos que os resultados da analyse de Withering se referem a 16 libras de agua e não a 8, será necessário concluir que a composição chimica das aguas das Caldas da Rainha se tem conservado constante durante o longo período de 74 anos, pois as differenças observadas em todas estas analyses podem caber nos limites dos erros admissiveis em trabalhos d'esta ordem " ${ }^{55}$. De facto, o problema residia nas diferenças de valores atribuídos à libra, onça e grão pelos analistas ingleses e portugueses.

Ao estudo feito, em 1884, por Santos e Silva sobre As Aguas Alcalino-Gazosas de Vidago (Fonte Campilho) é anexado uma memória de Raimundo da Silva Motta (1840-1910) [lente de Medicina na Universidade de Coimbra] Breves Consideraçóes Sobre as suas Qualidades e Usos Terapeuticos (figura 3). Fica-se a saber que o estudo tinha sido financiado pelo proprietário: «[...] O sr Augusto Cesar de Moraes Campilho [...] não receiou arriscar alguns capitaes na exploração d'uma nascente, de que é proprietário, correndo com as despesas de analyse, confiada a um dos nossos mais distinctos chimicos..." ${ }^{56}$. Sem nunca pôr em dúvida o rigor científico da análise feita por Santos e Silva, defende a necessidade de ensaios médicos pois [...] Se o clinico conhecer pela analyse quaes são os princípios mineralisadores de qualquer 
água, nem por isso fica sufficientemente habilitado a fazer uma prescripção racional [...] é indispensavel conhecer pela experiencia e observação prolongada os efeitos que ellas são capazes de produzir, quer no estado physiologico, quer em diversos estados pathologicos» ${ }^{57}$. Neste contexto, refere a realização de ensaios clinicos: [...] mandámos vir da fonte Campilho uma porção de garrafas [...] com o intuito de ensaiar clinicamente tanto no Hospital como na clinica particular [...] O distinto médico, dr. Coutinho, na sua clinica do Hospital da Universidade usou algum por tempo a água que lhe fornecemos, e colheu em alguns casos de dyspepsia, ligados a catarrhos gastro-intestinaes, resultados muito lisonjeiros..." ${ }^{58}$. Não há porém referência a descrições pormenorizadas destes ensaios. Segue-se a descrição de um conjunto de situaçôes em que achava apropriada a sua aplicação, quer por ingestão, quer em banhos.

Resultados e apreciações das análises de algumas destas águas aparecem publicados também na Coimbra Médica. É o caso designadamente das águas de Vale de Cucos [concelho de Torres Vedras] e das águas da Piedade ou de Fervença [concelho de Alcobaça]. Relativamente às primeiras a citada revista numa nota faz referência à publicação da obra "Guia das Aguas Mineraes dos Cucos" [Lisboa, Da Companhia Nacional Editora, 1892 (figura 4)] e chama a atenção do leitor para «[...] este Guia, onde encontra todas as informações sobre as aguas chloretadas sodicas dos Cucos, cuja analyse chimica foi comettida ao nosso amigo e illustre chimico, o sr. Santos e Silva» ${ }^{59}$ e cuja composição química aparece publicada no ano seguinte $(1893)^{60}$. Em 1894, são publicados, nesta mesma revista, os resultados da análise qualitativa e quantitativa das águas da Piedade ou de Fervença ${ }^{61}$ (figura 5).

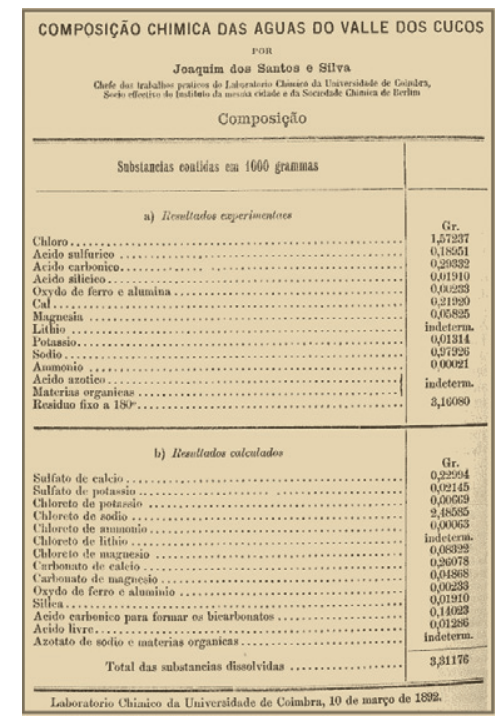

Figura 4 - Reprodução da separata sobre composição química das águas dos Cucos.

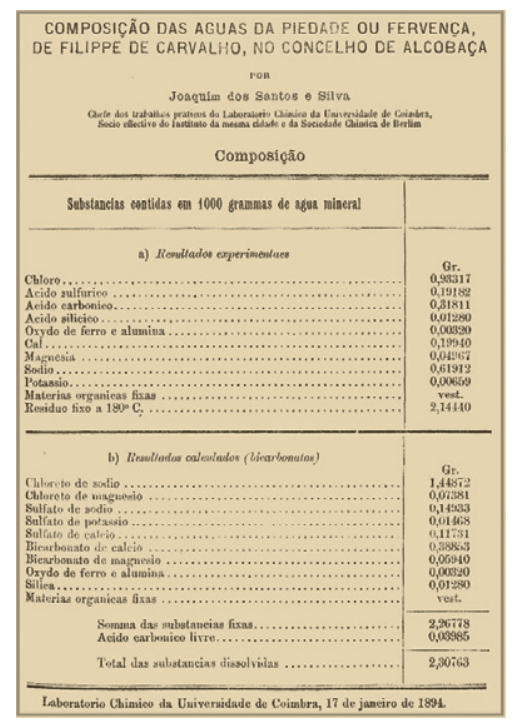

Figura 5 - Reprodução da separata sobre composição química das águas da Piedade. 
Santos e Silva, ocupou-se, durante quase 22 anos, no período entre 1878 e 1899, com a química toxicológica, em colaboração com investigadores da Faculdade de Medicina e procedido a numerosas análises toxicológicas ou químico-legais, a mando de juízes da comarca de Coimbra. A propósito da publicação do regulamento dos peritos médico-legais, na sequência da reforma dos serviços médico-legais já referida, teceu no seu artigo Toxicologia ${ }^{62}$, algumas considerações críticas sobre alguns dos artigos do referido regulamento, designadamente à adição ou não de álcool às vísceras, acrescentando porém: «[...] Quaesquer que sejam os aperfeiçoamentos realisados por esta reforma, é certo que ella marcou uma data importante n'a história da medicina legal do nosso paiz; e por isso pareceu-me opportuna a ocasião para conseguir aqui os resultados obtidos n'os exames toxicológicos de que pude colher, feitos n'o Gabinete de Chimica da Faculdade de Medicina e n'o Laboratorio Chimico da Faculdade de Philosophia da Universidade, durante o período já um pouco longo dos últimos quarenta anos ${ }^{63}$ [...] Vê-se pelo quadro precedente [figura 6] que n'o decurso de 40 annos se fizeram em Coimbra 294 exames toxicológicos [destes] 158, isto é, aproximadamente metade, ou seja 53,7\% são devidos ao envenenamento pelo arsénico; 46 ou 15,6\% deram diversos resultados diversos entre os quaes alguns não têm importância criminal [...] A estrychinina conta à sua parte 6 casos [...] Ao ácido oxálico são devidos dois casos [...] o fósforo só uma vez apareceu [...] Os 90 casos em que os resultados foram negativos dão $36,6 \%$; espero que com a reforma augmentará esta percentagem» ${ }^{64}$.

Em 1879, no seu artigo O Hydrogenio Sulfurado nas Investigaçôes Chimico Legaes, descreve o papel do ácido sulfídrico na precipitação do arsénio e outros elementos em análises toxicológicas ${ }^{65}$. Começa por tecer consideraçôes os processos de destruição ou transformação de matérias orgânicas em casos de análises toxicológicas, destacando o processo de destruição pelo ácido clorídrico e clorato de potássio aperfeiçoado, em 1844, por Carl Remigius Fresenius (1818-1897) e por August von Babo (1827-1894) em 1847, e designado por "processo de Fresenius e Babo", que consistia na junção às matérias suspeitas de ácido clorídrico e clorato de potássio com obtenção de um líquido que depois de filtrado era submetido à acção prolongado de gás sulfídrico que precipitaria o arsénio e outros elementos na forma de sulfuretos. Mas o objectivo de Santos e Silva não residia na discussão deste processo mas sim no facto do "[hydrogeneo sulfurado, que, sendo preparado por meio do sulfureto de ferro ordinario e do ácido sulfurico do commercio, ordinariamente inquinado com arsenico, póde conter hydrogeneo arseniado, o qual em presença do liquido suspeito, póde depositar sulfureto arsenico" "66. Desenvolve pois, em conjunto com Júlio Cesar de Sande Sacadura Botte (1838-1899) [professor substituto da Faculdade de Medicina da Universidade de Coimbra], uma série de experiências com a finalidade de verificar a pureza dos reagentes que deviam ser utilizados neste exame toxicológico, tendo concluído que: "[...] na preparação do hydrogeneo sulfurado por meio de ácido sulfurico e do sulfureto de ferro póde ser empregado um ácido arsenical, se sulfureto não contiver ferro no estado livre; no caso de existirem ao mesmo tempo as duas impurezas, ferro e arsenico, o hydrogenio sulfurado é arsenical e não póde se aplicado nas analyses de envenenamentos» ${ }^{67}$. 

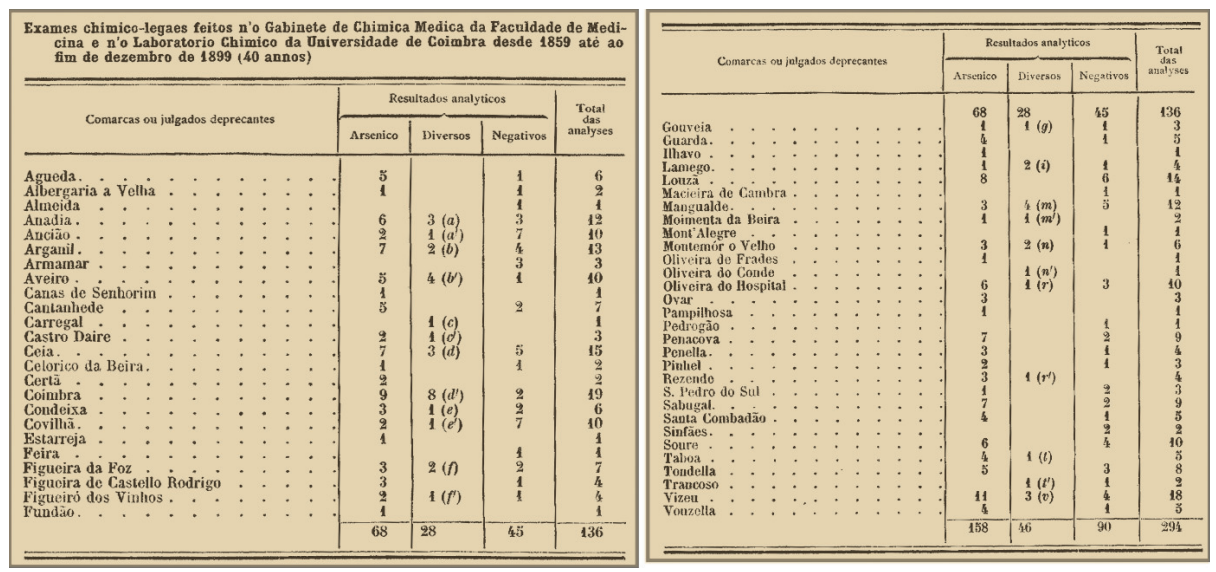

Figura 6 - Quadros integrados no artigo Toxicologia, Santos e Silva, 1900.

Um dos mais célebres casos de envenenamento, que abalou a opinião pública portuguesa no final do século XIX, foi o designado "Caso Urbino de Freitas". Vicente Urbino de Freitas (1849-1913) [depois de formado na Faculdade de Medicina da Universidade de Coimbra em 1875, exerceu clínica no Porto; em 1877 foi nomeado lente substituto da secção médica da Escola Médico-Cirúrgica, a cuja vaga concorreu com a dissertação $A$ teoria e a prática em medicina] foi considerado o principal suspeito da tentativa de homicídio de vários membros da abastada família da sua esposa, Maria das Dores Sampaio. Embora todas as vítimas apresentassem sintomas típicos de um envenenamento com alcalóides, só o seu sobrinho Mário Sampaio, acabou por falecer. De acordo com os registos da época, o ponto fulcral deste caso parecia ser a determinação da causa de morte do sobrinho de Urbino de Freitas.

O processo foi instaurado em 23 de Abril de 1890. Para tal, a foi nomeada uma comissão de peritos, da qual fazia parte o António Joaquim Ferreira da Silva (1853-1923) [à época lente na Escola Politécnica do Porto], Agostinho António de Souto e Manuel Rodrigues da Silva Pinto [ambos lentes da Escola Médica do Porto] e Joaquim Pinto de Azevedo [preparador de Anatomia da Escola Médica do Porto] que apresentam o seu relatório a 7 de Outubro (1890). Deste consta que os exames e as análises incidiram sobre as vísceras extraídas do cadáver do Mário na primeira e na segunda autópsia concluindo «...pela existência da delphinina, da narceina e da morphina e attribuiu a morte de Mário a estes três alcaloides constatados pelo exame medico..." ${ }^{68}$. Os advogados de defesa recorrem para a Relação do despacho de injusta pronúncia, chamam a conferência, ao Porto, Augusto António Rocha (1849-1901) [lente da faculdade de Medicina da Universidade de Coimbra, fundador dos Gabinetes de Microbiologia e Analises Clínicas, da Revista Coimbra Médica] que tinha sido colega de Urbino em Coimbra e convidam-no «a estudar o capítulo médico-legal do processo e a elucidá-los com o resultado desse estudo». Aceita a cooperação na defesa de Urbino mediante duas condições: a colaboração de Santos e Silva, e a consulta a eminentes toxicologistas do estrangeiro, designadamente Heinrich Berkurts [professor da Escola Politécnica de Brunswick], Ludwig Brieger, 
[professor da Universidade de Berlim], Hugo Mastbaum [lente da Faculdade de Ciências de Berlim e, na época residindo no nosso pais, na qualidade de químico analista e director do Laboratório Químico da 7a Região Agronómica de Lisboa]. Numa série de documentos compilados no suplemento da revista Coimbra Médica, Augusto Rocha e Santos e Silva criticam o relatório médico-legal e os seus proponentes afirmando "[...] que esses relatórios não deviam servir de base a um processo-crime» ${ }^{69}$. De facto, a uma pergunta do advogado de defesa [...] V. ex. ${ }^{\text {a }}$ conhece as contradições do relatório? [2a Testemunha, Augusto António da Rocha...] Ha algumas extraordinárias. Ha por exemplo, as que dizem respeito aos doseamentos. N'uma pagina diz se: 200 milligrammas de morphina; n'outra passagem apparece: 200 milligrammas de morphina e narceina; e assim successivamente. Ha, por exemplo, esta; n'uma parte os peritos dizem: tal reação approxima-se da reação da delphina; e mais adiante dizem: nós obtivemos a delphina necessária para as experiências physiologicas. De modo que, pelas reações que se aproximavam adquiriam o convencimento de que iam empregar um alcaloide puro em experiências physiologicas. Ha, por exemplo, esta: Symptomas que não se manifestaram, mas que deveriam ter existido" etc., etc. Emfim, as contradições abundam por toda a parte.» ${ }^{70}$. No mesmo sentido aponta o testemunho de Santos e Silva, quando questionado pelo advogado de defesa: «[...] V. ex. ${ }^{a}$ foi um dos peritos que analysaram e criticaram os trabalhos medico-legaes dos peritos portuenses. Diga-me v. ex. ${ }^{a}$ que defeitos encontrou n'esses trabalhos e as razoes porque os condemnou. [ $3^{\mathrm{a}}$ Testemunha, Joaquim dos Santos Silva...] As impressões que tive ao fazer a annlyse conservo-as ainda. Conclui que as reações alli apresentadas nao demonstram de forma nenhuma a existência dos alcaloides, que os peritos dizem ter encontrado. Com relação á urina, muitas vezes das analyses resultam confusões flagrantes; e com relação ás vísceras attendendo ao facto de ser admissivel a presença de productos da alteração cadavérica, não posso egualmente acceitar as conclusôes apresentadas pelos peritos..." ${ }^{71}$.

Desencadeia-se uma forte polémica entre peritos do Porto e os de Coimbra. Os peritos do Porto publicam Exame e refutação dos pareceres constantes dos suplementos à Coimbra Médica [cujo autoria é de Agostinho António de Souto] e mais tarde o Caso Médico Legal Urbino de Freitas ${ }^{72}$ (figura 7), com uma edição em francês [Relation Médico-Legale de L'Affaire Urbino de Freitas $]^{73}$, os de Coimbra continuam a campanha nos suplementos referidos, publicando em volume o Problema Médico Legal no Processo Urbino de Freitas, Uma Réplica ${ }^{74}$, subscrito não só pelos signatários dos suplementos, mas também por Silva Motta, Francisco João Rosa, [analista do Laboratório Higiénico de Lisboa] e Hugo Mastbaun (figura 8). E é nesse volume, em especial, que os peritos da defesa pretendem convencer de que venceram a competência científica, profissional e moral dos peritos da acusação. 


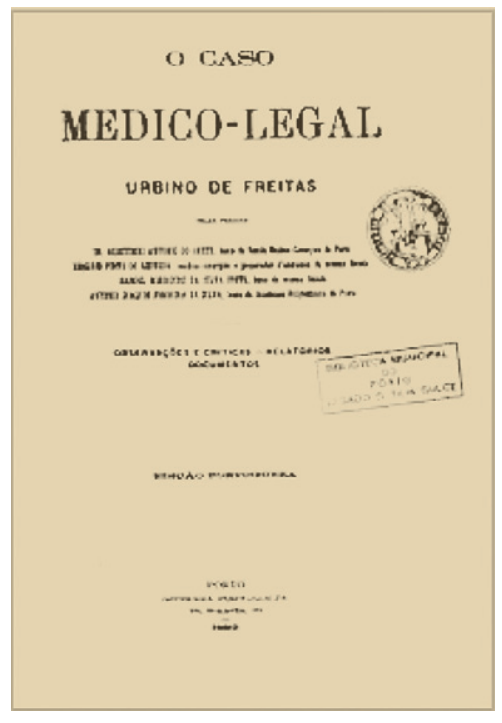

Figura 7 - Folha de Rosto: Caso Médico-Legal Urbino de Freitas de Agostinho António do Souto [e outros]

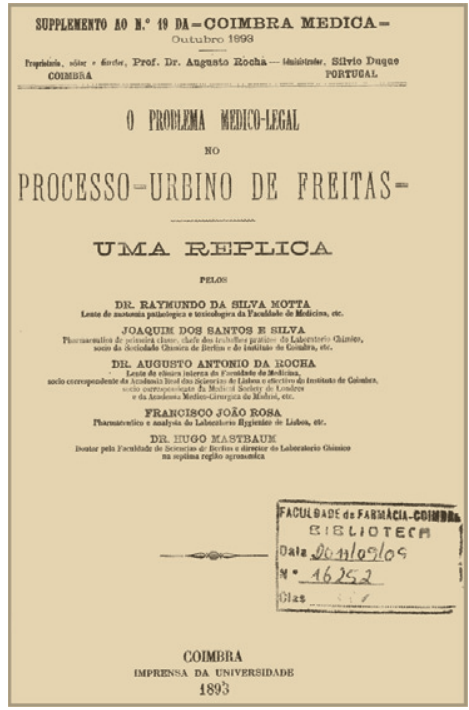

Figura 8 - Folha de Rosto: O problema medico-legal no processo-Urbino de Freitas: uma réplica, Raimundo Motta [e outros]

A disputa viria a ser ganha, pelo menos sob o ponto de vista legal, pelos peritos do Porto, conforme sentença proferida em 1 de Dezembro de 1893:

«... Condemno o mesmo reu Vicente Urbino de Freitas na pena de prisão maior cellular por oito annos, seguida de degredo por vinte annos, sem prisão no logar do degredo, ou na alternativa na pena de degredo por 28 annos, com prisãpor oito annos no logar do degredo, sendo em qualquer dos casos o degredo em possessão de $1^{\text {a }}$ classe» ${ }^{75}$.

No mesmo ano e em colaboração com António Augusto Costa Simões (1819-1903) [lente da Faculdade de Medicina da Universidade de Coimbra] Santos e Silva publica um breve estudo sobre o aparelho de Pettenkofer [Max von Pettenkofer (1818-1901)] existente no Gabinete de Fisiologia da Faculdade de Medicina [do qual aquele professor era director à época], destinado à determinação dos produtos de respiração de animais ${ }^{76}$. Descreve as vantagens instrumento relativamente aos anteriormente construídos e faz a descrição de uma série de procedimentos que lhe permitiriam determinar as quantidades designadamente de dióxido de carbono, água, hidrogénio e gases hidrocarbonados, produzidos. Conclui afirmando: «[...] por agora bastará dizer que as differentes experiencias a que, em comum com o sr. Dr. Costa Simôes, procedi com este aparelho, deram resultados satisfactorios no que diz respeito á determinação do acido carbónico»"

Valiosa foi também a contribuição de Santos Silva no material didáctico posto à disposição dos alunos. No curto período que Tollens esteve em Coimbra traduzira do alemão para o francês, para uso dos alunos que frequentavam o Laboratório Químico, um pequeno guia de Wöhler com o título Premiers exercices d'analyse chimique. Pouco depois de assumir o seu lugar, como já se referiu, publica em 1874 a obra Elementos de Analyse Chimica Qualitativa (figura 9). No prefácio lê-se: 
«Escrevendo estes Elementos de analyse chimica qualitativa, tivemos simplesmente em vista apresentar aos alunnos [...] um quadro resumido das reações principaes dos corpos que mais frequentemente se encontram, e da marcha sistemática que convém seguir quando se trata de chegar ao conhecimento da presença ou da ausência d'um qualquer d'estes corpos. Convencidos de que os tratactados completos de analyse chimica são menos próprios para guiar os alunos, que começam neste laborioso estudo [...] Não tem o nosso escripto o merecimento de coisa nova; mas tem uma forma que se nos representa como mais apropriada para uso dos principientes. Dê-se-lhe embora o titulo de compilação: exemplos deste género vimos muitos em diferentes laboratórios da Allemanha, e, convencidos da sua utilidade, buscámos imital-os» ${ }^{78}$.

Em 1884 aparece uma «segunda edição consideravelmente melhorada». Em Advertência escreve:

«Quando em 1874 publiquei estes elementos de Analyse Chimica, tive particularmente em vista prestar auxílio aos alumnos que frequentam o Laboratorio Chimico da Universidade [...] Era uma coleção de apontamentos que tinha feito para meu uso pessoal numa ephoca em que o estudo practico da analyse chimica estava pouco desenvolvido no Laboratorio da Universidade, e em que eram quasi desconhecidos no nosso paiz escriptos sobre esta especialidade além dos tractados de analyse de Rose, Fresenius, Chancel e Deschamps, todos pouco apropriados para o uso dos principiantes. A Faculdade de Philosophia da Universidade e a Escola Polytechnica de Lisboa, adotando o livro para compêndios dos seus respetivos cursos deram testemunho do apreço em que tomaram o meu humilde trabalho [...] Nesta segunda edição não alterei o plano primitivo, nem achei erros consideráveis para corrigir. Supprimi, porém, todas as reações que me pareciam de importância secundaria, e acrescentei grande numero de notas, que traduzem chimicamente as diversas reaçôes descriptas no texto, excetuando aquelas que, por serem mais complexas, ainda hoje são obscuras. E para que o livro possa também aproveitar aos alumnos que se dedicam particularmente aos estudos médicos, acescentéi-lhe uma terceira parte, na qual vão descriptas as operações necessárias para o descobrimento dos principaes venenos mineraes e orgânicos, assim como o ensaio qualitativo das urinas, dos sedimentos e dos cálculos urinários» (figura 10) ${ }^{79}$.

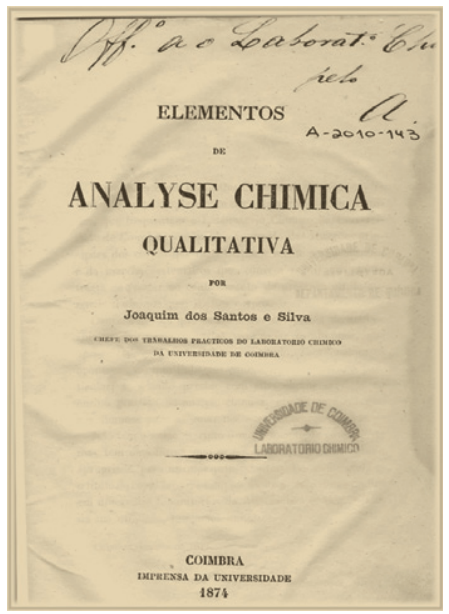

Figura 9 - Elementos de Analyse Chimica Qualitativa, 1874.

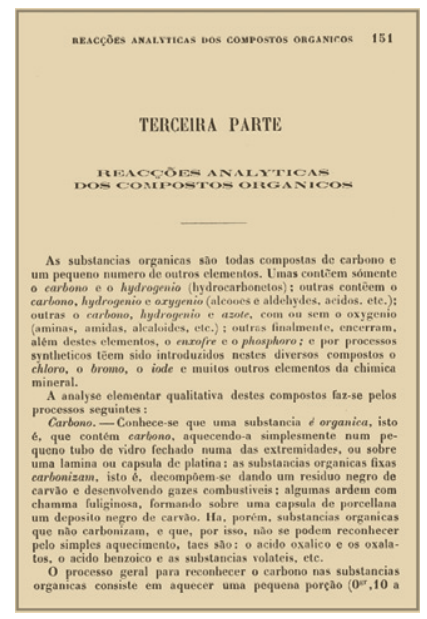

Figura 10 - Elementos de Analyse Chimica Qualitativa, 1891, Terceira Parte 
Em 1891, publica a 3. a edição acrescentado, à Advertência da edição anterior, "[... ] Publicando hoje a terceira edição deste livro, fiz apenas algumas correções e ampliações que me pareceram mais convenientes, sem alterar em coisa alguma o plano da edição anterior» ${ }^{80}$. Quando cuidava de preparar a $4 .^{\mathrm{a}}$ edição, surpreendeu-o a morte. Contudo, em 1906, é publicada a $4^{\text {a }}$ edição, contendo as alterações efectuadas por Santos Silva, com Advertência de Sousa Gomes, nela incluída: "O auctor faleceu deixando por concluir a presente edição do seu livro, de modo que a doutrina a partir de pag. 177 é reprodução do que se lê na $3^{\text {a }}$ edição, tendo-se suprimido aquellas partes que não se coadunavam com as alterações que o malogrado chimico introduzira nesta 4 a edição ${ }^{81}$.

É curioso notar que o livro é envolvido no "Caso Urbino". Os peritos do Porto no seu relatório [ponto 4] referem-se a "... contradicções flagrantes entre o livro do terceiro signatário [Joaquim dos Santos e Silva], Elementos de analyse chimica qualitativa, e as sua reflexões a propósito da analise toxicológica pendente» ${ }^{82}$ [...] É que os originaes peritos exigiam: a) que se fizesse a historia das doutrinas ptomainicas desde Selmi ou, melhor, desde Panum até Brigier, Fraenkel e Kitasato [Em nota de pé de página refere-se] Ferreira da Silva não conseguiu fazel-a numa serie de famosos artigos que publicou em a Medicina Contemporanea, n. ${ }^{\text {os }} 19$ e segg., 1892, e no Correio Medico, n. ${ }^{\text {os }} 9$ e segg., $1982 \ldots$; b) que se consignassem nos ensaios dos estudantes todos os reagentes que podem servir para reconhecer a morphina no meio de todas as impurezas, atravez de todas as peripécias de analise toxicológica [...] e) que se enumerassem todas albuminas, as suas reações e composição, e o mais atinente a este delicado, amplíssimo e contigente capitulo de chimica orgânica, quando se davam a estudantes simples noções sobre a mais trivial das albuminas, a albumina por excellencia; (f) que se entrasse nas subtilezas analyticas que levam a considerar um envenenamento como criminal ou accidental, como sucida ou homicida, etc.; g) que se formulassem as regras deontológicas ou jurídicas que obrigam os peritos a resevar authenticamente uma parte das materias suspeitas a apresentar ao tribunal a peça convincente. Sim. Os peritos reclamam perentoriamente que as vinte e três páginas, consagradas nos Elementos ao assunto [Elementos de Analyse Chimica Qualitativa, Terceira edição, Imprensa da Universidade, Coimbra, pp.157-180], contivessem toda a casuistica de toxicologia dos alcaloides!!» ${ }^{83}$.

Porém, como relatava Ferreira da Silva «Com este seu bom livro nacionalizou, digamos assim, o ensino da chimica analytica entre nós, escrevendo o primeiro guia de analyse chimica, urdido sob a base segura da experiencia e da pratica de laboratório» ${ }^{84}$. $\mathrm{Na}$ verdade, irá de servir de manual durante mais de trinta anos. [...] Com o mesmo pensamento de ser util aos alumnos da Universidade, redigiu ultimamente umas "Noçôes elementares de chimica pratica., para as preparações e experiencias sobre os principaes gazes e corpos da chimica mineral» ${ }^{85}$

É lhe também atribuída a obra Tabelas de fatores químicos para o cálculo de análises quantitativas, tomando para base os pesos atómicos de L. Meyer e K. Seubert [Faktoren-Tabellen zur Ausführung chemischer Rechnungen mittels der von L. Meyer und K. Seubert gegebenen Atomgewichte berechnet], impressa e publicada em Braunschweig por Friedrich Vieweg \& Sohn, em $1887^{86}$. Sobre ela apenas se conhece a recensão, muito elogiosa, seguinte: «Faktoren-Tabellen zur Ausführung chemischer Rechnungen [tabelas de fatores para a execução de cálculos químicos] mediante os pesos atómicos dados por L. Meyer e K. Seubert calculadas por Joaquim dos Santos e Silva, director das aulas práticas no laboratório químico da Universidade de Coimbra em Portugal. 
Braunschweig [Brunsvique] impressão e edição por Friedrich Vieweg und Sohn. 1887. Tabelas muito ricas que vão em breve obter direitos de cidadania sobretudo naqueles laboratórios em que se executa frequentemente análises de águas minerais e de outros materiais que contêm numerosos corpos químicos. O autor baseou os seus cálculos nos pesos atómicos rigorosos segundo Lothar Meyer e K. Seubert, conseguindo assim uma precisão incomparavelmente maior que aquela das tabelas semelhantes até agora disponíveis. O formato do livrinho de cerca de 100 páginas é tão maneiro quanto se deve poder esperar duma obra deste género» ${ }^{87,88}$.

Também numa nota escrita por ocasião do seu falecimento no jornal republicano Voz da Justiça se refere a obra Factoren Tabellen...:

«E' um trabalho de merito e de muita paciencia e calculo, que, pela sua boa organização presta ao chimico, nas suas analyses ponderaes, optimo serviço». E o autor prossegue nos elogios: «Havia n'elle muita originalidade; o seu trabalho era quasi exclusivamente seu, e quando por necessidade tinha que apresentar ideias de outrem, só o fazia depois de ter a certeza de não ser contradictado».

\section{E emocionalmente acrescenta:}

«...Não revelou nunca ignorância do seu sofrimento e nos últimos tempos conheceu, e fez vêr aos seus amigos d'um modo persuasivo que os seus dias estavam esgotados. $\mathrm{O}$ anno passado estando a veranear com a sua família na praia de Buarcos resolveu visitar Maiorca aonde tinha algumas propriedades e convidou o autor d'estas linhas para o acompanhar a uma d'essas propriedades: lá fômos e quando nos retirávamos ele quedou o passo e voltando-se para nós, disse-nos com serenidade: - «Vim acompanhado de um amigo despedir-me deste meu casal! [...] O seu rosto largo, dantes fortemente marcado por feições de homem forte e disciplinado, cobria-se de grande tristeza [...] Ao retirar-se, vimol-o desaparecer a distancia com o seu passinho miudo, a cabeça branca sob o chapéu de côco, sobrecasaca envolvendo-lhe o busto e o eterno guarda chuva, o companheiro de todos os filósofos, debaixo do braço» ${ }^{89}$.

\section{NotAS E BIBLIOGRAFIA}

${ }^{1}$ «[...] Foram presentes ao Conselho os seguintes requerimentos: Um de Joaquim dos Santos e Silva a fim de ser provido interinamente no lugar de Ajudante do Laboratorio Chymico que o Conselho indeferio por declarar o Snr Diretor deste estabelecimento que não havia já necessidade urgente de prover o mencionado lugar». Em Atas da Congregação da Faculdade de Filosofia (1860-1870), vol. 6, no verso da p. 57.

2. Júlio Máximo de Oliveira Pimentel (1809-1884), futuro Visconde de Vila Maior, matriculou-se na Universidade de Coimbra em 1826, nos cursos de Matemática e Filosofia. Envolveu-se nos movimentos civis que precederam o estabelecimento do regime liberal em Portugal pelo que se viu obrigado a abandonar, em 1828, os estudos. Regressou à Universidade em 1834, para terminar o curso de Matemática, o que alcançou três anos depois. Por concurso, foi nomeado em 1838 lente de química na Escola Politécnica de Lisboa, e regeu, também por concurso em 1853, a mesma cadeira no Instituto Industrial. Pouco depois do ingresso na Escola Politécnica, seguiu para Paris no prosseguimento de conhecimentos na área da química. Foram anos de estudo e trabalho intenso. Seguiu os cursos de Louis Joseph Gay-Lussac (1778-1850), e de Jean-Baptiste Dumas (1800-1884) e trabalhou nos laboratórios de Eugène-Melchior Péligot (1811-1890) e de Michel Eugène Chevreul (1786-1889). Em 1869 foi nomeado reitor da Universidade de Coimbra, lugar que ocupou até à sua morte. Deixou vasta obra publicada, sobretudo na área da Química e da sua aplicação industrial, nomeadamente, Liçōes de Química Geral e suas Aplicaçōes Principais, Relatório sobre as artes chimicas na exposição de Paris de 1855, Relatório sobre os vinhos na exposição de Paris de 1867, Relatório sobre o Estudo Químico do óleo de 
rícino, O Aluminium, Nota Científica, entre outras. Em Guilhermina Mota, Um Bolseiro em Paris em meados do século XIX: a preparação de um químico notável, o Visconde de Vila Maior, Congresso Luso-Brasileiro de História das Ciências, Universidade de Coimbra, 26 a 29 de outubro de 2011, Livro de Atas, pp. 260-278.

${ }^{3}$ CARVALHO, Joaquim Augusto Simões de - Memória Histórica da Faculdade de Filosofia. Coimbra: Imprensa da Universidade, 1872. p. 144-145.

4 "Aos treze dias do mês de novembro de 1868 reuniu o Conselho da Faculdade de Philosophia sob a presidência do $\mathrm{Ex}^{\mathrm{mo}}$ Conselheiro Jose Ernesto de Carvalho e Rego [do Conselho de Sua Magestade, Fidalgo Cavalleiro da Sua Real Casa, Commendador das Ordens de Christo e de Nossa Senhora da Conceição de Villa Viç̧osa, e da Imperial Ordem da Rosa no Brasil, Lente de Prima Jubilado da Faculdade de Theologia, exercendo as funçóes de Vice-Reitor (o lugar de Reitor estava vago)] estando presentes os $\mathrm{Sr}^{s} \mathrm{DD}^{\text {rs }}$ António [Antonino José Rodrigues Vidal, lente de prima, decano e diretor da Faculdade de Philosophia], Leão [Miguel Leite Ferreira Leão, Cathedratico da Faculdade de Philosophia e Diretor do Laboratorio Chimico], Simões [Joaquim Augusto Simões de Carvalho, Cathedratico da Faculdade de Philosophia], Jacintho [Jacintho Antonio de Sousa Cathedratico da Faculdade de Philosophia], Viegas [Antonio dos Santos Viegas, Substituto Ordinario da Faculdade de Philosophia], Albino [Albino Augusto Giraldes, Substituto Ordinario da Faculdade de Philosophia] e Manuel Paulino [Manuel Paulino de Oliveira, Substituto Ordinario da Faculdade de Philosophia]." Em Atas da Congregação da Faculdade de Filosofia (1860-1870), vol. 6, p. 121.

${ }^{5}$ Idem, p. 122.

6. Idem, verso da p. 123.

${ }^{7}$ Idem, p. 124.

${ }^{8}$ Idem, verso da p. 125.

${ }^{9}$ Idem, verso da p. 125 e p. 126

${ }^{10}$ FORMOSINHO, Sebastião - Nos Bastidores da Ciência 20 anos depois, Coimbra: Imprensa da Universidade de Coimbra, p. 82.

${ }^{11}$ Atas da Congregação da Faculdade de Filosofia (1860-1870), ob. cit., p. 140.

${ }^{12}$ CARVALHO, Joaquim Augusto Simões de, ob. cit., pp. 187-188.

${ }^{13}$ Idem, p. 189

${ }^{14}$ Atas da Congregação da Faculdade de Filosofia (1860-1870), ob. cit., verso da p. 140.

15 Roberto Duarte Silva (Santo Antão, Cabo Verde 1837 - Paris 1889) formou-se na Escola de Farmácia de Lisboa. Em 1862, foi para Paris, onde frequentou os cursos de química de Charles Adophe Wurtz (1817-1884), Henri Étienne Sainte-Claire Deville (1818-1881), Marcellin Pierre Eugène Berthelot (1827-1907) e de Antoine Jérôme Balard (1802-1876). Depois de se licenciar em física, torna-se discípulo de Wurtz, em 1863. Colaborou em numerosos trabalhos de investigação em Química Orgânica, sobretudo com outro discípulo de Wurtz, Charles Friedel (1832-1899). Em 1871 ingressa no laboratório de seu amigo Friedel na École de Mines, em 1873 é nomeado Chef de travaux de Chimie Analytique na École Centrale des Arts et Métiers e em 1882 professor da então fundada École de Physique et Chimie Industrielle de la Ville de Paris. Recebeu em 1885 o Prix Jecker da Academia das Ciências de Paris. Entre outros cargos foi eleito 1887 Presidente da Societé Chimique de Paris. A. Carneiro e R. Herold em http://www.spq.pt/docs/Biografias/ RobDuarteSilva_port.pdf ${ }^{16}$ Atas da Congregação da Faculdade de Filosofia (1860-1870), ob. cit., p. 140.

${ }^{17}$ Idem, p. 142.

${ }^{18}$ Adriano de Paiva Leite Brandão obteve o título de Bacharel pela Faculdade de Matemáticas, aos 19 anos, e o de Doutor em Filosofia em 1868, com a tese intitulada "Geologia, Apreciação das Causas Atuais", na Universidade de Coimbra. Porém, em 1872 foi nomeado lente da nona cadeira (Química) da Academia Politécnica do Porto, tendo transitado depois para a sexta cadeira (Física) onde desenvolveu a sua atividade docente e investigativa. Em CARVALHO, Rodrigues Guedes 1998. História do Ensino da Engenharia Química na Universidade do Porto (1762-1905), Porto: FEUP Ediçôes, p. 587.

${ }^{19}$ Atas da Congregação da Faculdade de Filosofia (1860-1870), ob. cit., verso da p. 142.

${ }^{20}$ Reitoria da Universidade, Ofícios (1870-1876), verso da p. 30 e p. 31.

${ }^{21}$ SILVA, Joaquim Ferreira da, 1906, Joaquim dos Santos Silva, Necrologia, Revista de Chímica Pura e Aplicada, $2^{\circ}$ ano, $n^{\circ} 3$, p. 117.

${ }^{22}$ Idem, p. 118

${ }^{23}$ COHEN, Ernst - Jacobus Henricus van't Hoff, Sein Leben und Wirken. In OSTWALD, Wilhelm, coord. Grosse Männer, Studien zur Biologie des Genies. Leipzig: Akademische Verlagsgesellschaft, 1912.

${ }^{24}$ van't Hoff (nessa altura com 19 ou 20 anos) estava enganado: Joaquim dos Santos e Silva já tinha 30 anos em 1872.

${ }^{25}$ Tradução de B. J. Herold da tradução alemã do nerlandês.

${ }^{26}$ SILVA, Joaquim Ferreira da 1906, ob. cit., p. 118.

${ }^{27}$ PITA, João Rui - A Escola de Farmácia de Coimbra (1902-1911). Coimbra: Imprensa da Universidade de 
Coimbra, 2000. p. 58.

${ }^{28}$ Carta de Lei no 186 . Diário do Governo. (1899-08-21)

${ }^{29}$ Decreto-Lei no 274. Diario do Governo. (1899-12-02)

${ }^{30}$ Carta de Lei no 280. Diario do Governo. (1902-12-11)

${ }^{31}$ Publicado no Diario do Governo, no 280, de 11 de dezembro de 1902, p. 4046.

32 Anuário da Universidade de Coimbra 1903-1904, p. 232; Idem, 1904-1905, p. 197; Idem, 1905-1906, p.21.

${ }^{33}$ FORMOSINHO, Sebastiāo - Nos Bastidores da Ciência 20 anos depois. Coimbra: Imprensa da Universidade de Coimbra, 2007. p. 92

${ }^{34}$ WHITE, Lynn 1962, Medieval Technology and Social Change, Oxford: Oxford University Press, p. 40; citado por KNIGHT, David, Ideas in Chemistry. A History of the Science, Londres: The Athlone Press, 1995, p. 62.

${ }^{35}$ SILVA, Joaquim Santos e, Ueber die Brom-camphocarbonsäure, 1873, [Aus dem chem.. Institut der Universität Bonn; mitgeteilt von Aug. Kekulé], Berichte der deutschen chemischen Gesellschaft, vol. 6, pp. 1092-1093.

${ }^{36}$ ANSCHÜTZ, Richard - August Kekulé, Band I, Leben und Wirken. Berlin: Verlag Chemie G. m. b. H., 10, 1929.

${ }^{37}$ KAUFFMAN, George B. - Julius Bredt and the Structure of Camphor: On the Threshold of Modern Stereochemistry, Journal of Chemical Education. Vol. 60 (1983), p. 341-342.

${ }^{38}$ SILVA, Joaquim dos Santos e - Estudo Chimico d'alguns derivados da camphora. O Instituto. Coimbra: Imprensa da Universidade. Vol. XVIII (1873) p. 220-227.

${ }^{39}$ Idem, XX, pp. 18-23.

${ }^{40}$ SILVA, Joaquim dos Santos e - Ensaios Chimicos sobre a Essencia da Pimenteira Falsa. O Instituto. Vol. XX (1874), p. 209-213, p. 246-254.

${ }^{41}$ SILVA, Joaquim dos Santos e 1877 - Breve Notícia sobre a Riqueza das Quinas Cultivadas nas Possessões Portuguezas da Africa. O Instituto. Vol. XXIV (1877), p. 29-32.

42 SILVA, Joaquim dos Santos e - Nova Analyse das Quinas da Ilha de S.Thomé, 1881. O Instituto. Vol. XXVIII (1877), p. 71-73.

${ }^{43}$ PITA, João Rui, ob. cit., p. 60.

${ }^{44}$ SALGADO, José Pereira - A Química e a Física em Portugal. In Exposição Portuguesa em Sevilha. Lisboa: Imprensa Nacional, 1929. Vol. II. p. 12-13.

${ }^{45}$ Os nossos mestres, Notícias Farmacêuticas, vol. 4, 1938, pp. 211-213. O autor queria referir-se ao Reitor da Universidade de Coimbra Visconde de Vila Maior.

${ }^{46}$ SILVA, Joaquim dos Santos e - As águas Férreas da Estrada da Beira. O Instituto. Vol. XXI (1875), p. 219.

${ }^{47}$ Idem, p. 219.

${ }^{48}$ Idem, pp. 218-219.

${ }^{49}$ Idem, pp. 221

${ }^{50}$ Idem, XXI, pp. 224-227, pp. 254-266; XXII, pp. 19-22.

${ }^{51} \mathrm{Um}$ estudo bastante desenvolvido dos ensaios realizados e publicados na revista $O$ Instituto de Coimbra é citado em LEONARDO, António José F., MARTINS, Décio R., e FIOLHAIS, Carlos, 2011, O Instituto de Coimbra e a análise química de águas minerais em Portugal na segunda metade do século XIX, Química Nova, 34, (6), pp. 1094-1105.

${ }^{52}$ Os resultados estão publicados nas Memórias da Academia das Ciências de Lisboa, 1850, Tomo 2, 2a série, p. 177.

${ }^{53}$ Um resumo da análise está publicado nos Anais de Ciências e Letras da Academia das Ciências de Lisboa, 1858.

${ }^{54}$ Os resultados da análise estão integrados no relatório intitulado Trabalhos preparatorios acerca das aguas minerais do Reino e providencias do Governo sobre proposta da Commissão respetiva, Lisboa: Imprensa Nacional, 1867.

55 SILVA, Joaquim dos Santos e - Aguas Thermaes das Caldas da Raínha. O Instituto. Vol. XXIV (1876), p. 164.

${ }^{56}$ SILVA, Joaquim dos Santos e - Analyse Chimica de uma Agua de Vidago Recentemente Descoberta. O Instituto. XXXI (1884), p. 380.

57. Idem, p. 381.

58. Idem, p. 384.

${ }^{59}$ Nota sobre Guia das Águas Mineraes dos Cucos, 1892, Coimbra Médica, n. ${ }^{\circ}$ 14, p. 224.

${ }^{60}$ SILVA, Joaquim dos Santos e - Hidrologia Médica, XII, Composição Chimica das Águas do Valle dos Cucos. Coimbra Médica. n. ${ }^{\circ} 19$ (1893), p. 292.

${ }^{61}$ SILVA, Joaquim dos Santos e 1894, Hidrologia Médica, XIV, Composição Chimica das Águas da Piedade ou de Fervença, de Fillipe de Carvalho, concelho de Alcobaça, Coimbra Médica, n. ${ }^{\circ}$ 10, p. 163.

${ }^{62}$ SILVA, Joaquim dos Santos e - Toxicologia. Coimbra Médica. p. 178-182.

63. Idem, p. 180. Em nota de pé de página informa «Os resultados dos exames toxicológicos feitos n’o Gabinete de Chimica da Faculdade de Medicina e n’o Labotatorio da Faculdade de Philosophia desde 1850 até 1871, 
acham-se consignados no Instituto, de 1872 (vol. XV, p. 53). Os dos exames feitos desde 1871 ate ao fim de dezembro de 1899 foram extrahidos do Livro de registos dos relatórios toxicológicos, em que colaboraram diversos professores da Faculdade de Medicina e (desde 1878) o signatário d'estas linha».

${ }^{64}$ Idem, pp. 180-182.

${ }^{65}$ SILVA, Joaquim dos Santos e - "O Hidrogénio Sulfurado nas investigaçōes Chimico-Legaes". O Instituto. Vol. XXVI (1879), p. 265-269.

${ }^{66}$ Idem, pp. 266-267.

${ }^{67}$ Idem, p. 269.

${ }^{68}$ LA-GRANGE, Antonio - Audiencias de Julgamento do Dr. Urbino de Freitas.Porto: Typ. De Arthur Jose de Sousa \& Irmão, 1893. p. 203-206.

${ }^{69}$ ROCHA, Augusto; SILVA, Joaquim Santos e - O problema medico-legal no processo Urbino de Freitas. Documentos Compilados. Coimbra Médica. Suplemento ao n. 2 (Jan. 1892), p. VIII.

${ }^{70}$ LA-GRANGE, Antonio, ob. cit.,p. 312.

${ }^{71}$ Idem, p. 351.

${ }^{72}$ SOUTO, Agostinho António do; AZEVEDO, Joaquim Pinto de; PINTO, Manoel Rodrigues da Silva [et al.] - O Caso Medico-Legal Urbino de Freitas: Observaçōes e criticas. Relatórios documentos. Porto: Imprensa Portugueza, 1893.

${ }^{73}$ SOUTO, Agostinho António do; AZEVEDO, Joaquim Pinto de; PINTO, Manoel Rodrigues da Silva [et al.] - Relation Médico-Legale de L’Affaire Urbino de Freitas. Édition française. Porto: Typographia Occidental, 1893.

${ }^{74}$ MOTTA, Raymundo da Silva, [et al.] - O problema medico-legal no processo - Urbino de Freitas: uma réplica. Coimbra: Imprensa da Universidade, 1893.

${ }^{75}$ LA-GRANGE, Antonio, ob. cit., pp. 203-206

${ }^{76}$ SILVA, Joaquim dos Santos e - Breve Notícia sobre o Aparelho de Pettenkorf. O Instituto. Vol. XXVI (1879), p. 165-169, 214-216.

77 Idem, p. 216.

${ }^{78}$ SILVA, Joaquim dos Santos e - Elementos de Analyse Chimica Qualitativa. Coimbra: Imprensa da Universidade, 1874 .

${ }^{79}$ SILVA, Joaquim dos Santos e - Elementos de Analyse Chimica Qualitativa. 2.a ed. Coimbra: Imprensa da Universidade, 1883.

${ }^{80}$ SILVA, Joaquim dos Santos e - Elementos de Analyse Chimica Qualitativa. 3.a ed. Coimbra: Imprensa da Universidade, 1891.

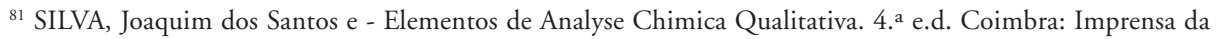
Universidade, 1906.

82 SOUTO, Agostinho António do et al., ob. cit, p.

${ }^{83}$ MOTTA, Raymundo da Silva et al., 1893, ob. cit., pp. 10-11

${ }^{84}$ SILVA, António Joaquim Ferreira da, ob. cit., p. 119.

${ }^{85}$ Idem, p. 120

${ }^{86}$ SILVA, Joaquim dos Santos e - Faktoren-Tabellen zur Ausführung chemischer Rechnungen mittels der von L. Meyer und K. Seubert gegebenen Atomgewichte berechnet. Braunschweig: Druck und Verlag von Friedrich Vieweg und Sohn, 1887.

${ }^{87}$ JEHN, Carl - Faktoren-Tabellen zur Ausführung chemischer Rechnungen mittels der von L. Meyer und K. Seubert gegebenen Atomgewichte berechnet von Joaquim doz Santos e Silva, Leiter der praktischen Uebungen im chemischen Laboratorium der Universität Coimbra in Portugal. Archiv der Pharmazie. Braunschweig: Druck und Verlag von Friedrich Vieweg und Sohn. 226:11 (1887), p. 520.

${ }^{88}$ Tradução do alemão de Bernardo J. Herold.

${ }^{89}$ Cardoso e Sousa, "Joaquim dos Santos e Silva"- A Voz da Justiça. № 343, Anno 40 (1 de março de 1906). 